\title{
TUTELAS Y CURATELAS EN LA ÉPOCA MODERNA: UN ESTUDIO DE CASOS EN LAANDALUCÍA RURAL (S. XVIII)
}

\author{
Raquel Tovar Pulido* \\ UNIVERSIDAD DE EXTREMADURA
}

\begin{abstract}
RESUMEN
Se aborda la figura de la mujer andaluza como tutora y curadora de los hijos menores, al tiempo que se encarga de administrar los bienes que estos han heredado. Para ello, se analizan fuentes notariales del siglo XVIIII, procedentes de los Archivos Históricos Provinciales de Córdoba y Jaén. En especial se estudia la importancia de la representación legal para la transacción de las propiedades que administraban las madres, ante la incapacidad de obrar de los niños.
\end{abstract}

PALABRAS CLAVE: tutela y curaduría, herencia familiar, protocolo notarial, minoría de edad, representante legal, siglo XVIII

Enviado: 8/06/2020

Aceptado: 29/09/2020

*rtovarp@unex.es 
ISSN: 0212-5099

E-ISSN: 2695-7809

DOI: 10.24310/BAETICA.2020.v1i40.9548

\title{
GUARDIANSHIP AND CURATORSHIP IN MODERN TIMES: A CASE STUDY IN RURAL ANDALUSIA (18TH CENTURY)
}

\author{
Raquel Tovar Pulido* \\ UNIVERSIDAD DE EXTREMADURA
}

\begin{abstract}
This essay analyzes the figure of the Andalusian woman as tutor and curator of the minor children. Mothers administered the assets inherited by their daughters and sons. To do this, have been observed some notarial sources from the 18th century, they are kept in the Provincial Historical Archives of Córdoba and Jaén. In particular, it is studied the importance of the legal representation for the transaction of the properties administered by the widows, because of the legal inability to act of the children.
\end{abstract}

KEYWORDS: guardianship and curatorship, family heritage, notarial protocol, minority of age, legal representative, century XVIII

Enviado: 8/06/2020

Aceptado: 29/09/2020

*rtovarp@unex.es 


\section{INTRODUCCIÓN}

La temática que gira en torno a los derechos del menor ha suscitado numerosas polémicas en las últimas décadas ${ }^{1}$. La investigación histórica nos permite comparar la evolución que ha sufrido la figura del niño en distintas épocas y cómo en algunas zonas marginales del tercer mundo parece que no se hubieran producido grandes avances, dada la miseria y la violencia a la que se ven sometidos. No obstante, en la última centuria ha habido intentos por parte de los poderes públicos de los países más avanzados por protegerlos a través de distintos documentos institucionales y gubernamentales: Declaración Universal de Derechos de 1948; Declaración Universal de los Derechos del Niño, 1959; Carta Social Europea de 1961; Carta Europea de los Derechos del Niño y el Convenio de la Haya de 1993; así como la Declaración de los Derechos del Niño de 1995. En España los derechos de los menores son avalados por la Constitución de 1978, aunque posteriormente ha habido cambios e intentos por parte del legislador, trabajando para que la legislación establezca una protección del menor ${ }^{2}$.

Cuando los menores quedan desamparados, el tribunal designa un tutor para tomar decisiones médicas y financieras, de manera que la persona incapacitada pierde el derecho legal de decidir. Dicho tutor tiene la guarda y protección de una persona, por lo que se encarga de gestionar su patrimonio y de atenderle en sus necesidades personales. Mientras que el curador solamente toma decisiones financieras ${ }^{3}$. Distinguiríamos así entre

1. Este trabajo forma parte del proyecto de investigación Individualismo moderno. Escenarios familiares de emergencia de la identidad personal en el occidente moderno peninsular (1700-1850) (referencia HAR2017-84226-C6-3-P), plan nacional I+D del MINECO.

2. Ley Orgánica de 1996 (sujeto de derechos en el proceso penal). Además de la protección, estos documentos citados promueven la autonomía del menor, pues no se adquiere la capacidad de obrar de un día para otro, sino de manera progresiva. Hoy en día, en España, la figura de la "emancipación" coloca al menor entre la minoría y la mayoría de edad (en la actualidad, a partir de los 16 años puede emanciparse y ser responsable de su vida, con limitaciones patrimoniales, aunque pueda disponer de sus bienes).

3. La patria potestad era un derecho subjetivo del pater familias que procede del Derecho Romano. Es una potestad que el derecho positivo atribuye a los progenitores para el cuidado del menor (art. 154 del Código Civil, 1889, vigente desde entonces hasta la actualidad). Por tanto, la guarda y custodia ha de realizarse en beneficio de los hijos y no de los padres, de ahí que destaque la irrenunciabilidad e irretransmisibilidad. Implica velar por sus hijos y tenerlos en su compañía. Históricamente la patria po- 
dos conceptos: la capacidad jurídica, que es la aptitud para ser titular de derechos $\mathrm{u}$ obligaciones por el mero hecho de haber nacido (heredero de los bienes de sus padres), de modo que el heredero y legitimario es el hijo ${ }^{4}$; mientras que la capacidad de obrar es la posibilidad de ejercer esos derechos y obligaciones, lo cual ocurre cuando se llega a la mayoría de edad.

Respecto al marco cronológico que abordamos en este artículo, las investigaciones acerca de la tutela y la curaduría legal de los niños y de los jóvenes menores de edad se perfila en un ámbito todavía por explorar en profundidad, dado que se trata de una fase de lo más interesante para el estudio de la familia moderna, pero que, sin embargo, es muy poco conocido. El estudio de la infancia y de la juventud ha despertado escasa atención en el ámbito de la producción historiográfica europea, si bien no ha pasado del todo desapercibido en el interior castellano, aunque se trata de una realidad desconocida prácticamente en el sur peninsular ${ }^{5}$. El significado de la designación de representantes legales deriva de la necesidad de asegurar una protección a los huérfanos, en sus necesidades alimenticias y de vestuario, pero también en la gestión de los patrimonios que les habían sido legados, pero que ellos no podían todavía administrar. Esta realidad era algo común en todos los sectores sociales, si bien en función de las circunstancias económicas se regulaban, por un lado, los sistemas educativos que les eran facilitados y, por otro lado, las posibilidades de medro social,

testad recaía en el padre y solo subsidiariamente en la madre (hoy se distingue entre titularidad -conjunta- e individualidad en el ejercicio por uno de los progenitores, en supuestos coyunturales o de carácter permanente). Asimismo, el Código Civil implica la obediencia filial al pater familias y el respeto, incluso extinguida la patria potestad. En cuanto al patrimonio, los menores tienen la titularidad de la propiedad pero incapacidad para venderla o alquilarla, de modo que los padres lo administrarán (art. 164 del Código Civil) -casos en los que el hijo adquiere herencia, donación o legado, por el testador causante o sucesión legítima-. Ante la ausencia de los padres, se nombra tutor por orden de prelación (la abuela etc), siempre han de ser personas físicas o jurídicas y sin ánimo de lucro, para menores e incapacitados. Vide C. Lasarte Álvarez (2019).

4. Para recibir una herencia es necesario aceptarla y reunir requisitos de capacidad, por lo que un menor no tiene conciencia de lo que hace, es donde entra la representación de la madre u otros familiares.

5. Algunos de los trabajos más destacados al respecto a nivel europeo son: G. Levi y J. C. Schmitt (dirs.) (1996), A. Redondo (ed.) (1996), Ch. Bouneau et C. Le Mao (dirs.) (2009), P. S. Fass (ed.) (2003), B. Roberts (2004) y (2006), B. Roberts y L. Groenendijk (2005), Ph. Ariès (1987), R. Ago (1996), S. Pierrer (1995), M. a G. Cava López (2000), A. Merchán Álvarez (1976) y F. NúÑez Roldán (2011). 
pues especialmente en el caso de la mujer joven y doncella era fundamental que dicho patrimonio se viera reflejado en la dote $^{6}$.

En la Castilla rural del Antiguo Régimen, la familia se constituía como el espacio jurídicamente regulado de la patria potestad paterna, por lo que el progenitor tenía la función de hacerse cargo del patrimonio familiar. De manera que, ante la ausencia del padre, la práctica legal recurría a la tutela y curatela como sistema de protección, con el objetivo de que las personas designadas fueran las encargadas de decidir por el futuro inmediato de los menores que se encontraban a su cargo, pero también de aquellos bienes que poseían ${ }^{7}$. Generalmente se producía la ratificación por vía testamentaria de la tutela en la figura de la madre de los niños, en la que recaía la cesión del usufructo de las haciendas y la gestión de las propiedades heredadas, fueran bienes muebles, inmuebles (casas, locales y fincas) o ganado. Se procuraba de esta manera que las condiciones de vida de los niños se vieran continuadas en el ámbito familiar. No obstante, cabía una excepción, si la viuda volvía a contraer matrimonio perdía sus derechos de tutela, con ello se pretendía que los bienes de los hijos no fueran gestionados por personas ajenas a la familia, en este caso el padrastro. En este sentido, en contra de lo que la legislación establecía, muchas madres que habían contraído segundas nupcias, reclamaron para sí la custodia de sus hijos y bienes, en detrimento de los tutores establecidos al margen de la unidad nuclear ${ }^{8}$.

Ante la ausencia de ambos progenitores, la administración de los bienes recaía en los familiares más allegados y estos eran nombrados a través de las cláusulas testamentarias ${ }^{9}$. No obstante, a menudo se generaba una pro-

6. M. García Fernández (2016), 27-30.

7. A. Arbiol (1715). P. Melgarejo (1704), 237-244, vide Libro Segundo: 'De tutelas, inventarios y todo género de particiones y cuentas' y 'Tutores'. Á. RodríGUEz SÁNCHEZ (1990), 365-380.

8. En la Castilla interior, durante la época moderna, las mujeres desempeñaron el papel de tutoras en dos terceras partes con respecto al total de los nombramientos. En cuanto a los allegados tutores, en la provincia de Valladolid, se observa en los entornos, a finales del Antiguo Régimen, la presencia de vecinos, miembros de la abogacía local versados en leyes y clérigos. M. García Fernández (1995), 296-302.

9. "En Francia en ocasiones se requería de asambleas o juntas de parientes, constituidas para resolver la designación de los defensores de los menores". M. García Fernández (2016), 31-33.

En Galicia se ha documentado la existencia de negativas, por parte de tíos y primos de los jóvenes, a asumir la responsabilidad de tales cargos. Ello justificaba una mayor presencia allí de vecinos y extraños al universo familiar en este cometido (hasta un $11 \%)$. En ocasiones solo se aceptaban las designaciones bajo el apremio de los tribu- 
blemática cuando los representantes designados realizaban una mala gestión, que tendía a un cierto aprovechamiento lucrativo personal, en perjuicio de los menores ${ }^{10}$. A tal punto que fueron frecuentes los pleitos civiles en las Chancillerías castellanas porque los tutores no habían cumplido lealmente con sus compromisos de salvaguarda, inversión y acrecentamiento de los patrimonios, de quienes -debido a su juventud- eran inhábiles para administrarlos ${ }^{11}$.

La preocupación de la normativa legal castellana por establecer un sistema de garantías para los huérfanos se pone de manifiesto a través de los documentos notariales ${ }^{12}$. En lo que respecta a las fuentes empleadas para nuestro trabajo, hemos procedido al análisis de varios protocolos notariales de los Archivos Históricos Provinciales de Jaén (AHPJ) y Córdoba (AHPC) que nos aproximan a las gestiones de administración patrimonial realizadas por las mujeres, que habían sido nombradas tutoras de sus hijos menores. Concretamente, solicitudes de permisos para vender, arrendamientos y reconocimientos de censos sobre propiedades agrícolas. Se trata de varios relatos que nos permiten ilustrar cualitativamente las necesidades a las que tenían que hacer frente las viudas, las cuales en muchos casos dependían de lo que le rentaban tales propiedades para hacer frente a las penurias económicas por las que atravesaban, una vez que había desaparecido del hogar la fuerza de trabajo y el sustento que normalmente constituía el pater familias. Estas experiencias individuales nos permitirán mostrar algunos ejemplos de mujeres tutoras y curadoras de varias poblaciones rurales andaluzas, con respecto a los patrimonios de los menores.

nales y las autoridades competentes. Vide "Tutela, Familia, Infancia y Administración del patrimonio", en I. Dubert García (1992), 241-250.

10. "Se produjo un incremento de la aceptación por parte de amplios colectivos sociales de la tutoría reclamada por la madre nuevamente casada. Dichas disposiciones de confianza en el provecho de los intereses de los huérfanos revelan el reconocimiento de la labor educativa, afectiva y administrativa que se esperaba de ellas". M. GARCíA FERNÁNDEZ (2016), 31-33 y 35.

11. Aquellas actuaciones populares aumentaron su reiteración con el paso del tiempo de forma significativa en los espacios controlados por el tribunal de justicia. Los curadores (ad litem más que ad bonam) aparecieron involucrados muchísimo más habitualmente que los propios tutores. M. García Fernández (2016), 35, 37 y 39.

12. "Los testamentos y las actas notariales derivadas del proceso de discernimiento y aprobación tutelar trataban de solventar la sensible cuestión de la atención patrimonial y personal juvenil". De hecho, las tutelas ordenadas en las últimas voluntades aumentaron con una tendencia consolidada en la segunda mitad del siglo XVIII. M. GARCíA FERNÁNDEZ (2016), 31-33. 


\section{LA LEGISLACIÓN RELATIVAA LA TUTELA Y CURATELA EN EL ANTIGUO RÉGIMEN}

El fallecimiento del esposo dejaba a la mujer casada y a los hijos menores en un marco jurídico de desamparo, para cuyo sostenimiento desempeñaba un importante papel el control de los patrimonios familiares. La mujer accedía entonces a la jefatura del hogar, cuya patria potestad había ejercido el marido difunto, de manera que solo a partir de esta tragedia familiar las viudas administraban en solitario la casa y la economía doméstica. En este orden de cosas, la legislación castellana puso de manifiesto su preocupación por la desprotección de los menores y se ocupó de la elaboración de un cuerpo normativo dirigido a la atención a la orfandad. Las disposiciones legales establecieron las medidas procesales que se debían adoptar para evitar el expolio de los bienes que habían heredado de sus progenitores $\mathrm{u}$ otros familiares.

Durante la época moderna se mantuvieron las figuras, de larga tradición jurídica, de la tutela y de la curaduría, como instrumentos jurídicos esenciales en la defensa de los intereses patrimoniales de los menores. No obstante, la tutela no era únicamente una institución ordinaria para la guarda y custodia de huérfanos no emancipados o de aquellos niños cuyos padres estuvieran privados de la patria potestad, como el caso de las viudas que se habían vuelto a casar, sino que también se ocupaban de adultos que habían sido incapacitados por el padecimiento de enfermedades mentales o de otro tipo (locura, sordomudez o demencia). Asimismo, ambas figuras eran conferidas por el Derecho Civil y fueron creadas en interés de la familia ya en época romana ${ }^{13}$. El tutor era el defensor y guardador del huérfano pupilo menor de 14 años, por lo que se encargaba del cuidado y protección de su persona y defensa de su patrimonio ${ }^{14}$. Por su parte, el curador se ocupaba de los intereses económicos de los menores de entre 14 y 25 años, por lo que no se le exigía la existencia de relaciones o preocupaciones de tipo personal ${ }^{15}$. En ambos casos debían defenderles en pleitos. Asimismo, se

13. M. García Fernández (2013), 92-93.

14. En Extremadura, G. Cava señala que en la mitad de los casos los bienes del padre son transmitidos a los hijos adolescentes, en las disposiciones hereditarias e instrucciones ligadas al destino de las haciendas. M. a G. CAVA LóPEz (1999), 65-98.

15. El derecho castellano vigente en la época moderna englobaba como menores a aquellos que no han cumplido los 25 años, si bien la niñez abarca de los 0 a 12 años para mujeres y hasta los 14 años para los hombres, siendo el periodo restante hasta alcanzar los 25 años el de la "juventud”. J. Febrero (1828), 156-162. 
establecían escrituras de fianza con juramento y se realizaba un inventario de bienes ante escribano público.

\subsection{Características de la tutela}

Uno de los tipos de tutela era el sistema automático de designación de tutor, donde se incluyen la testamentaria y la legítima: por un lado, la tutela testamentaria era otorgada por el testador a favor de los hijos legítimos, póstumos, naturales u otros herederos extraños. Generalmente recaía la tutela en el cónyuge sobreviviente, de hecho la viuda fue excusada en muchas ocasiones del pago de fianzas para dicho ejercicio. En su ausencia, abuelos, tíos y hermanos mayores fueron los nombrados para encargarse de los menores, tratando de priorizar entre los varones; aunque también podían ejercer tales funciones personas ajenas al tronco familiar, como clérigos, amigos y vecinos. En este ámbito, era frecuente la elección compartida de al menos dos tutores. Por otro lado, la tutela legítima se trataba de una fórmula supletoria que se producía en ausencia de testamento; se daba a los parientes del pupilo según un orden de prelación por parentesco.

El segundo tipo de tutela era el sistema no automático, al que se asociaba la dativa, que era determinada por la autoridad judicial. Se producía en ausencia del sistema automático y podían intervenir en la elección de los tutores los mismos parientes ${ }^{16}$.

\subsection{Características de la curatela}

En lo que respecta a la curatela también seguía el orden de preferencia legítima, testamentaria y dativa. Los legítimos se elegían por nombramiento del padre o abuelo en testamento, no pagaban fianza ni requerían confirmación por el juez ordinario; mientras que los dativos se adjudicaban por parentesco y requerían discernimiento judicial de su cargo (preferencia de la madre -aunque esta fuera menor de 25 años-y después conforme el grado de consanguinidad).

Algunos menores pedían la "emancipación" de sus tutores con anterioridad al cumplimiento de la mayoría de edad. "La justicia podía concederlo para que definiesen su futuro: era el tiempo de la oficialía, los novicios pasaban a ser frailes, los estudiantes alcanzaban sus grados o se casaban”. M. García Fernández (2013), 90.

16. Los cuidados de un tutor diferente al progenitor requerían de un mayor control en las cuentas. También se regulaba la presencia del menor en la residencia del tutor, que podía ser de manera transitoria o permanente. M. García Fernández (2013), 94 y 97. 
Su duración podía ser ilimitada, por lo que tenían derecho a pedir la liberación de su cargo transcurridos cinco años, siempre que no se tratara de cónyuges o ascendientes (padres y abuelos). Se encargaban de la administración de los bienes y de la representación en pleitos, si bien también cabía la posibilidad de nombrar curadores ad litem, dedicados específicamente a los pleitos ${ }^{17}$.

\subsection{La gestión del patrimonio por ambas figuras jurídicas}

La correcta gestión de la herencia era de vital importancia para proporcionarles un lugar donde vivir, alimentos y educación. En cualquier caso, como depositario de la confianza legal de la familia, la responsabilidad de ambas figuras no se limitaba a preservar la propiedad, sino que se estipulaba la conveniencia de procurar el incremento de la hacienda, a través de inversiones en la compra de censos o propiedades rústicas, así como en la venta de los frutos producidos. La regulación de su compromiso se llevaba a cabo mediante el juramento en el cargo ante el juez o escribano. En el ejercicio de sus responsabilidades como sustitutos de los progenitores, se comprometían a elaborar y presentar inventario de bienes y relación de cuentas, así como no podían proceder a la venta o enajenación de las propiedades, salvo licencia previa emitida por el juez y siempre con el motivo de sufragar las deudas contraídas por el padre, casar a los hijos o solventar otros compromisos ineludibles ${ }^{18}$.

La normativa legal del Derecho castellano entendía de extrema importancia la precisión de las obligaciones y derechos reconocidos para garantizar los intereses del menor. Se procuraba asegurar la idoneidad de las personas que serían designadas y, más allá de la figura de la madre viuda, entre los demás familiares se tendía a la exclusión para el ejerci-

17. La aceptación y juramento por el discernimiento sólo se eximía si se era hidalgo, mayor de setenta años o si ya tuviese tres tutelas. M. García Fernández (2013), 92-93.

18. La infancia constituía un periodo delicado a nivel psicológico y emocional, por lo que había que ser cuidadosos con quiénes eran las personas que se encargarían de su cuidado. No obstante, a veces se llegaba al extremo de que nadie quería hacerse cargo de ellos, lo cual resultaba devastador para los pequeños. En la diócesis de Coria, Cava López constata prácticas para la adjudicación de los menores huérfanos mediante pregón público, a los interesados en su manutención o su acogida en régimen de soldada, a cambio de la remuneración en metálico o del usufructo de la hacienda de aquellos (Acebo, Hoyos y Robledillo de Gata). Existía un traspaso y liberalización de responsabilidades tributarias que en el siglo XVI se fijaba en periodos de 14 meses, en el siglo XVII de hasta 27 meses y 36 meses en el siglo XVIII, dada la coyuntura de incertidumbre y precariedad económica. M. a G. CAVA López (1999), 72, 91 y 97. 
cio de la tutela -en teoría- a mujeres, menores, discapacitados físicos o psíquicos, deudores y acreedores del pupilo, así como a los miembros de determinados grupos sociales o de actividad -religiosos, administradores de rentas reales, caballeros y soldados ${ }^{19}$.

Fuera de la unidad nuclear, los parientes consanguíneos eran los elegidos como tutores y curadores ${ }^{20}$. No obstante, no cabe duda de que las designaciones tutelares entre parientes consanguíneos fuera de la unidad nuclear suponían una carga considerable que muchos intentaron eludir apelando ante la justicia por motivos varios, como la enfermedad, la distancia en el grado de parentesco o la incompatibilidad por el desempeño de otras ocupaciones ${ }^{21}$. De modo que, para mermar las cargas de la custodia de los pupilos, la ley contemplaba ciertos incentivos de tipo económico que hacían más atractiva tal responsabilidad, pues la administración de los bienes favorecía a los tutores con el derecho a la décima parte de los rendimientos obtenidos por los bienes naturales, industriales y civiles del menor, no como usufructuarios a título lucrativo, sino como acreedores ${ }^{22}$.

\subsection{EI discernimiento}

No podemos finalizar este apartado sin hacer mención al discernimiento, que es el acto jurídico a través del cual el juez nombraba al tutor o curador y le hacía conocedor de sus deberes y obligaciones con respecto a los menores tutelados. En los casos analizados sobre viudas, tales menores eran sus propios hijos y su autoridad sobre los mismos se producía una vez muerto el esposo.

En Alcaudete, a 5 de junio de 1755, se produjo un discernimiento a favor de la viuda doña Josefa Montes, como tutora de su hija menor, doña María Antonia, que tuvo con don Francisco Mazuelos, para que administrara y cobrara

19. "Eran sujetos carentes de las facultades requeridas para la eficaz gestión de los asuntos encomendados, cuando no una presumible mala predisposición hacia el menor, caso de los deudores del mismo". M. ${ }^{a}$ G. CAVA López (1999-2000), 265 y 267-268.

20. Sobre las implicaciones de las relaciones de parentesco vide J. L. FlandRIN (1976), 19-67.

21. La propia esfera jurídica la califica como "gravoso cargo" al que no obstante "todos pueden ser competidos (...) porque es oficio público y necesario". J. Febrero, 166.

22. Siendo conscientes de este interés económico, los padres dejaban estipulado que los tutores que habían nombrado por manda testamentaria quedaran exentos de la presentación de fianzas, tratando de eludir también el encarecimiento de los costes protocolarios que ello ocasionaba, por parte de las autoridades judiciales. M. G. CAVA LóPEZ (1999-2000), 269 y 271. 
los bienes de dicha menor ${ }^{23}$. En 1752 doña Josefa Montes y Cervantes era una viuda labradora de 42 años, que vivía en la calle Pontanilla. Tenía una hija, dos mozas sirvientas que ganaban 20 ducados, dos mozos para la labor, los cuales ganaban 100 ducados anuales y las esposas de estos dos también residían en la casa. Además, tenía otras seis viviendas y algunas tierras de regadío, olivares y siembra de cereales, así como una extensa cabaña ganadera de más de dos centenares de cabezas de ganadería ovina, porcina y caballar ${ }^{24}$. Asimismo, otro ejemplo que hemos encontrado también en Alcaudete -el 17 de diciembre de 1764 - es el discernimiento a favor de María de Heredia-viuda-, como tutora y curadora de los bienes de Manuel Carmona, su hijo menor ${ }^{25}$.

23. AHPJ, año 1755, número 32873, fol. 149. Escribano Juan Manuel Álvarez. Jaén. Alcaudete. Doña Josefa Montes. Discernimiento (otorgamiento) a favor de doña Josefa Montes, viuda, 5 de junio de 1755.

24. Vivía en una casa portal, con cocina, bodega, cuarto, sala, dos caballerizas, corral, cuatro cámaras, (20x30) por su alquiler se ganarían 10 ducados. Desglosamos a continuación el resto de sus propiedades: casa en dicha calle, portal, cocina, caballeriza, cuarto, corral, y por alto una sala, dos cuartos, tres cámaras $(5 \times 15)$ valor del alquiler 8 ducados; casa en dicha calle, caballeriza, pajar, corral con tres olivos y cuatro frutales, (6x30) alquiler 4 ducados; casa portal, pajar, caballeriza, (4x6) alquiler 2 ducados; casa en calle Corredera, portal, 3 cuartos, azotea, (4x3) alquiler 6 ducados; casa en calle Fuente Nueva, portal, cocina, cuarto, caballeriza, corral, cámara, $(4 \times 20)$ alquiler 4 ducados; casa en calle Carretas, portal, 2 cocinas, 3 cuartos, un lanero, una caballeriza, 2 corrales, y por alto 3 cuartos, 3 cámaras, (10x20), alquiler 8 ducados; casa en calle Barrionuevo, portal, cocina, 2 cuartos, caballeriza, corral, 2 cámaras $(8 \times 20)$, alquiler 4 ducados.

Su propiedad agrícola se constituye de seis fincas que suman 12 fanegas, unas 8 hectáreas aproximadamente y 225 cabezas de ganado. Tierra de sembradura y secano: 4,5 celemines de $1 .^{\mathrm{a}}$ calidad, año en medio; 1,5 fanegas de $1 .^{\mathrm{a}}$ calidad, año en medio; 8 fanegas de $3 .^{\text {a }}$ calidad, cada 2 años. Tierra de sembradura de secano y olivos: 2,5 fanegas de secano, 3 celemines con 12 olivos de 2. ${ }^{\text {a }}$ calidad, 4 con 16 estacas de la misma que no producen, y una fanega y 11 celemines de la misma cada 2 años. Tierra de regadío y olivar: 10 celemines de $2 .^{\text {a }}$ calidad, 40 olivos de la misma, no se siembra. Tierra de secano y estacas de olivo: 10 celemines de $3 .^{\text {a }}$ calidad, 69 estacas, no producen y no se siembra. Ganado: 2 caballos, 3 mulas, 94 ovejas a 9 reales (946 reales); 5 carneros (55 reales); 61 borregos (671 reales); 25 cerdas a 10 reales cada una (250 reales); 36 cerdos (1.080 reales); 47 colmenas a 7 reales cada una (329 reales), lo cual hace un montante de todo por un valor de 1.425 reales. AHPJ, Catastro del Marqués de la Ensenada, Libros de Bienes, Alcaudete, fols. 825 y ss.

En 1761 vendió más de la mitad de su explotación ganadera y algunos inmuebles. Vendió la casa por la que ganaba ocho ducados, otra por la que ganaba cuatro ducados, 40 olivas, 2 caballos, 94 ovejas, 5 carneros y 61 borregos. Archivo General de Simancas (AGS), Comprobaciones de Alcaudete. s/f.

25. AHPJ, número 32874, año 1764, fol. 230. Escribano Juan Manuel Álvarez. Jaén A1caudete. Discernación a favor de María de Heredia viuda, 17 de diciembre de 1764. 
No obstante, nos parece oportuno introducir como ejemplo la existencia de tutelas sobre hijos de otros familiares, aunque la viuda ya posea la patria potestad sobre sus propios vástagos. Es lo que le ocurrió precisamente a la viuda de 40 años, residente en Linares, Francisca Antonia de Medina. Era la cabeza de familia de un hogar en el que mantenía a sus cinco hijos menores $\mathrm{y}$, además, era tutora de otros cinco menores, que eran sus sobrinos e hijos de su difunto hermano Juan Antonio Medina ${ }^{26}$. Vivían todos en la misma casa, pues la vivienda era propiedad de ambos hermanos, de modo que sus sobrinos también eran herederos del inmueble ${ }^{27}$.

\section{MUJERES TUTORAS Y CURADORAS}

La presencia de la viuda en las funciones de tutela y curaduría se pone de manifiesto de manera general sobre el cuidado de los hijos, tras la muerte del esposo. Incluso, aunque no se le otorgara tal derecho y obligación jurídicamente porque volviera a casarse, en la práctica se ocupaba de criar y educar a sus vástagos. No obstante, como se ha mencionado, las segundas nupcias podían hacer recaer la tutoría en el nuevo esposo de la mujer, lo cual podría implicar un riesgo para la conservación del patrimonio familiar, tal y como se observaba desde el ámbito jurídico y se hace alusión a la dejación de las responsabilidades de gestión de las haciendas ${ }^{28}$.

Se observa, en este sentido, una diferencia sexual que refleja el signo discriminatorio hacia la mujer por parte de la normativa jurídica, pues la desaparición de la madre no perturbaba el ejercicio de la patria potestad, en la medida en que le correspondía por derecho al varón, incluso aunque contrajera matrimonio nuevamente ${ }^{29}$. Por el contrario, la mujer sólo podía

26. La normativa del siglo XVI establecía que se podía excusar de ser tutor el que tuviera cinco hijos o más vivos. También si estos hubieran muerto en guerra por defensa de su república. Además, eran excusables algunos cargos: recaudador de rentas reales o ausentes por alguna causa conveniente al consejo; juez o alguacil $u$ oficio público semejante. Asimismo, la edad, la situación económica y la responsabilidad sobre otras tutelas influían en la obligación de aceptar una nueva tutoría (ser mayor de setenta años; ser muy pobre, enfermo o ignorante; mantener pleito con el pupilo o tener otras dos tutelas a su cargo). G. Monterroso y Alvarado (1571), 209-210. Se analiza esta cuestión a través del prohijamiento y la tutela en la Málaga moderna en el trabajo de A. MARChAnt Rivera (2009).

27. AHPJ, Catastro del Marqués de la Ensenada, Libro de Legos, Linares, fol. 678.

28. M. ${ }^{a}$ G. Cava LóPez (1999-2000), 272-276.

29. Del mismo modo, ya desde época bajomedieval, el Derecho catalán impone a la madre tutora testamentaria o legítima condiciones que no se exigen a los hombres. C. Forns DE RIVERA (1997), 53-63. 
ser tutora de sus propios hijos si su cónyuge no se oponía a ello por vía testamentaria y siempre que no se celebraran segundas nupcias ${ }^{30}$. En este orden de cosas, es muy importante que seamos conscientes de los condicionantes a los que se veían sometidas las mujeres en atención a su estado civil $^{31}$, pues solo las viudas presentaban capacidad de obrar, mientras que las casadas y solteras tenían limitada su capacidad de acción por la autoridad marital y paterna, salvo cuando, ante la ausencia de estos, se encontraban al frente del hogar ${ }^{32}$. Pero ¿de qué aparato legal se valían para administrar el patrimonio de sus hijos las viudas tutoras y curadoras?

\subsection{El poder notarial como elemento facilitador de la administración de los bienes}

Los protagonistas de este relato son los niños y, sin duda, la realidad en la que se vieron inmersos ante la desaparición de su progenitor varón supuso una fractura familiar, cuyas consecuencias económicas serían de mayor calado en los hogares más humildes ${ }^{33}$. Su aparente voluntad respecto a su patrimonio recaía en la representación legal por parte del tutor, que como se ha mencionado se encargaba de velar por sus intereses ${ }^{34}$. No obstante, no se trataba de un asunto tan fácil ${ }^{35}$, sobre todo si se era mujer, pues para llevar a efecto determinadas gestiones patrimoniales requerían de un poder notarial, mediante el que designaban a un tercero que se encargaba de representarlas en el acto jurídico ${ }^{36}$.

También en Italia, durante los siglos XIII-XV, es vigilada la tutela de la madre mediante supervisión y colaboración de los varones de la línea agnaticia del menor. N. GUGLIELMI (1988), 157-171.

30. Sin embargo, sobre las madrastras las disposiciones señalan de manera positiva su labor educativa y la capacidad de ejercer las mismas funciones de las madres. A. RodríGuez SÁNCHEZ (1990).

31. A. M. Froide (2005), 1 y ss.

32. M. M. ${ }^{\text {a }}$ Birriel Salcedo (2019), 71-72. Sobre la literatura del miedo a las mujeres sin tutela masculina y los modelos de conducta estrictos para ellas vide M. VigIL (1986).

33. F. García GonZÁlez (2007).

34. F. J. Alfaro Pérez (2019), 314-315. Sobre esta cuestión vide J. A. Salas Auséns (2014).

35. Los representantes legales de las esposas eran los maridos. F. J. Alfaro Pérez (2019), 320.

36. El estudio de las fuentes notariales nos permite aproximarnos a la realidad social y económica de la sociedad modernista, además de a los aspectos de tipo jurídico. En esta línea, las escrituras de apoderamiento forman parte del Derecho Privado de la época y nos revelan los negocios jurídicos para los que se empleaban. M. Martín JimÉnez DE MuÑana (1993), 375. 
Los poderes notariales constituyen la autorización que una persona (poderdante) otorga a otra persona física o jurídica (apoderado), de forma pública ante notario, con el fin último de que pueda llevar a cabo determinados actos jurídicos y materiales en su nombre. Por consiguiente, se fundamenta en una plena relación de confianza, si bien no le autoriza a tomar decisiones en contra de su voluntad. Así pues, es un documento público por el cual el notario legitima al representante legal como mediador dando fe de ello, pero sin responsabilidad sobre lo pactado. Asimismo, no es un contrato entre dos partes, sino que tiene un carácter unilateral y puede ser revocable por distintos motivos, bien porque ya no sea necesario o bien porque se pierda la confianza en el apoderado por parte del poderdante, así como por fallecimiento ${ }^{37}$. En cualquier caso, el poder para administrar bienes dota de plenos efectos en la esfera jurídica al apoderado, para gestionar el patrimonio de la persona a la que representa de manera temporal o permanente ${ }^{38}$.

Tales intercambios en la representación legal han dejado evidencias documentales que hacen posible conocer las características de la propiedad y de la renta de las mujeres del siglo XVIII. Concretamente, la carta de poder supone la cesión de plena potestad para diversas funciones de naturaleza jurídica o contractual, relativas a la propiedad como compraventas, arrendamientos y administración de bienes, además de pleitos y tutorías ${ }^{39}$. Así, la documentación notarial asentada en los Libros de Protocolo analizados nos ha permitido sacar a la luz varias tipologías de documentos públicos, entre los que encontramos permisos para vender, reconocimientos de censos, así como cartas de arrendamientos ${ }^{40}$.

37. El artículo 1.712 del Código Civil distingue entre poderes generales y poderes especiales: los primeros facultan a otra persona para que pueda realizar todos los actos o negocios jurídicos que se requieran (se exceptúan los personalísimos como el testamento). Por su parte, los poderes especiales designan el bien jurídico concreto sobre el cual va a recaer la acción y la naturaleza del acto que se permite (por ejemplo, compraventa de una casa).

En la actualidad, en España las revocaciones de poderes se recogen en un archivo público notarial, para que cualquier notario pueda verificar si el poder que se le presenta está vigente. Á. ZúÑIGA (2013), 64-65.

38. Á. ZÚNIIGA (2013), 67-68.

39. J. L. Pereira Iglesias y M. Rodríguez Cancho (1982), 194 y 200.

40. "Alfonso X el Sabio, en su obra legisladora del siglo XIII, otorgó al notariado castellano una importancia y un valor administrativo que lo convirtieron en una de las instituciones de mayor representación social en todo el panorama civil del reino". Las Partidas recogen las atribuciones que otorgó a los escribanos públicos: la fides publica 


\subsection{Las compraventas}

Una de las tipologías de carácter delegado y representativo entre el otorgante del poder y el representante eran las cartas de pago y las cartas de obligación de compra venta. Por un lado, las primeras suponen una relación entre comprador y vendedor y el pago se efectúa en el instante, sin que el vendedor y el comprador se conviertan en acreedor y deudor. La operación comercial se produce mediante pago en dinero o también por cambio, mediante trueque o permuta. Por otro lado, las cartas de obligación de compraventa son transacciones que suponen una venta mediante pagos aplazados entre el acreedor y el obligado deudor ${ }^{41}$. Sin embargo, para llevar a término la venta de los bienes de sus hijos las mujeres necesitaban pedir permisos, por lo que además de los poderes para vender, se otorgaban permisos a petición de viudas que eran tutoras y curadoras de los bienes de sus hijos pero que, por distintas circunstancias, querían vender las tierras y las casas que estos vástagos habían heredado del padre difunto o de otros familiares. De modo que, como no eran las propietarias, sino las administradoras de tales bienes, habían de pedir un permiso para proceder a su traspaso.

El testimonio de la siguiente mujer de Linares es claro acerca de las penurias que pasaban las viudas y de la necesidad de vender propiedades para obtener un dinero, con el que poder mantenerse a ellas y a sus hijos durante algún tiempo. En 1760 María Guerra Lozano, viuda de Juan Rojano de Vilches, figuraba en un protocolo notarial donde indicaba ser madre, tutora y curadora de sus hijos menores, Antonio y Alfonsa Rojano. Sabemos por la información del Catastro que, en 1752, se recogía que era una mujer pobre, de 25 años y con dos hijos menores, la hija Alfonsa Rojano -de ocho años- y el hijo varón -de tres años-. Por lo que en el momento de la redacción del poder ella tendría 32 años aproximadamente y los hijos 15 y 10 años respectivamente. En el documento decía que su fallecido esposo había heredado de sus padres difuntos, Antonio Rojano e Ildefonsa María de Vilches, una sexta parte de casa proindivisa con otras tres sextas partes de Martín Santoia Merino y María López Rojano -su mujer-, y con otra sexta parte de Manuela Barea -viuda de Juan García Rojano-; y otra sexta parte de Manuel Rojano.

o capacidad de autenticar los negocios (cualquier escritura otorgada en su presencia, suscrita y signada por él hacía fe y se la tenía por auténtica entre partes, ante terceros, así como en juicios,). C. Gómez López (2017), 479 y 487.

41. J. L. Pereira Iglesias y M. Rodríguez Cancho (1982), 194-195. 
La casa estaba situada en la calle Niño Jesús y tenía un censo de 400 reales a favor de la cofradía de nuestra señora del Carmen. Alegaba que por su estado no tenía con qué alimentarse ni alimentar a sus hijos. Además, uno de sus dos vástagos padecía hacía un mes un acreciente de tabardillo y tenía que hacer frente a la enfermedad, pero "no hallaba asilo ni modo de mantenerse y hacer frente a los gastos" ${ }^{\prime 2}$. Por este motivo, no le quedaba otro recurso que el de vender la sexta parte de casa, con cuyo importe no sería de mayor consideración por estar la casa deteriorada, de modo que decía así: "nos podremos alimentar de las miserias". Por tanto, para poder buscar quién comprare dicha casa, que se practicara con la formalidad y seguridad, pidió licencia para poder vender. No firmó porque declaró no saber leer ni escribir ${ }^{43}$.

Ejemplos similares los encontramos en otras localidades de Jaén, como la villa de Porcuna, donde la viuda Beatriz Bueso, en 1766, como tutora y curadora de sus hijos menores, pidió que se le concediera licencia para vender 1,5 fanegas "para su diaria manutención y como decencia de su persona" 44

En la misma villa, en 1776, después de casi 20 años de viudez, doña Theresa Delgado y Cumbrera indicaba que era la viuda de don Manuel Gallo Aguilera y decía que el 30 de noviembre de 1757 hizo testamento su marido. Cuando murió la había dejado como tutora y curadora de sus hijos menores. En el momento del testamento los dos vástagos que tenían eran menores, después quedó embarazada de otro al que se le mejoraría de 60 celemines. Así, esta mejora recayó en su hijo menor, Manuel Gallo. Pero después tuvieron a Silvestre y "lo había criado con mucho trabajo y necesidad por la pobreza, por lo que por la decencia y manutención de su hijos menores" quería vender esas tierras, de manera que pidió licencia para vender los dichos 60 celemines $^{45}$.

42. Según el Diccionario de la Lengua Española (en línea, 2020), el tabardillo también es conocido como tifus. Se trata de una enfermedad infecciosa grave, que se caracteriza porque el que la padece sufre fiebre alta, delirios y la aparición de unas costras negras en la boca, así como manchas punteadas en la piel.

43. AHPJ, Protocolos notariales, número 15.147, años 1758-1760, fol. 17. Escribano Rodrigo José Alaminos. Jaén. Linares. Año 1760. María Guerra Lozano, viuda de Juan Rojano de Vilches, 24 enero de 1760. En el año 1761 las Comprobaciones del Catastro no aportan información acerca de esta mujer.

44. AHPJ, Protocolos notariales, número 10.166, años 1765-1773, fol. 143. Escribano Alonso José Matías. Jaén. Porcuna. Año 1766. Beatriz Bueso, viuda de Manuel Bellido, 5 septiembre de 1766 .

45. AHPJ. Protocolos notariales, número 10.166, años 1765-1774, fol. 304. Escribano Alonso José Matías. Jaén. Porcuna. Año 1776. Doña Theresa Delgado y Cumbrera, viuda de don Manuel Gallo Aguilera, 25 de septiembre de 1776. 
El modelo de familia predominante en la Andalucía del setecientos, al igual que sucedía en el interior y mediodía peninsular, era la familia nuclear ${ }^{46}$. De manera que cuando fallecía el esposo, la tipología más común en los hogares encabezados por viudas seguía siendo la misma, ya que estaba formado por esta y sus descendientes no emancipados aún, los cuales a menudo eran niños muy pequeños o jóvenes que no habían alcanzado la mayoría de edad ${ }^{47}$. Estas circunstancias las empujaron muchas veces a poner en venta lo poco que habían heredado en bienes raíces, si bien a veces la

46. En el reino de Granada en el siglo XVIII la familia nuclear superaba las tres cuartas partes de los hogares, dato que es similar al modelo existente en Extremadura, CastillaLa Mancha y Castilla-León. F. García GonzÁlez y D. Maldonado (2019), 137.

En el reino de Jaén, en el siglo XVIII, las viudas en la jefatura del hogar se caracterizaban por encabezar familias nucleares (más del $50 \%$ en Vilches), si bien también eran numerosas las solitarias $(26,79 \%$ en dicha villa), por lo que el promedio de edad era de 50 años. Las de edad más avanzada tenían hijos mayores que se habían marchado del hogar tras contraer matrimonio, pero las más jóvenes debían hacer frente al sostenimiento del hogar en el que vivían sus hijos pequeños, algunos de muy corta edad. Menos del 90 \% ejercían un oficio fuera del ámbito doméstico; algunas eran labradoras y otras se dedicaban a trabajos artesanos. R. Tovar Pulido (2014-2015), 414.

No obstante, el $55 \%$ de un conjunto de villas analizadas del reino de Jaén poseían tierras, de modo que contaban con medios agrícolas con los que abastecerse. R. Tovar Pulido (2017a). Aun así, es de destacar que labradoras y hacendadas concentraban el 46,41\% de las tierras en posesión de viudas, aunque representaban el 6,62\% de mujeres cabezas de familia. R. Tovar Pulido (2018a), 323 y 326.

47. En la Granada rural de la época, el número medio de personas en los hogares encabezados por mujeres es de 2,9 en el Valle de Lecrín. En la comarca se sitúa en 3,8 con cabeza de casa masculina. M. M. ${ }^{a}$ Birriel Salcedo (2019), 63.

Se observan en Trujillo agregados domésticos extensos entre las viudas más acaudaladas, con presencia de parientes (sobrinos, madres ancianas...), además de criados, frente a la familia nuclear tradicional, con mayor predominio entre las clases más humildes.

R. Tovar Pulido (2017b), 426.

En cuanto al tamaño medio de los hogares masculinos, también en Trujillo se ha constatado que la familia nuclear suponía un $66,52 \%$, frente al $11,26 \%$ de solitarios. $\mathrm{R}$. Tovar Pulido (2018b), 147.

En esta ciudad el número de hijos oscila entre 1,2 en las familias de militares y profesionales liberales y 1,77 en los hogares encabezados por artesanos y jornaleros (promedio de 1,4 en todas las familias de la ciudad). Los grupos más humildes solían tener paradójicamente más hijos que las familias acaudaladas y con mayores recursos. En conjunto, el agregado doméstico de las élites era de 3,02 frente a 3,26 miembros por familia del resto de la población, a pesar de que los primeros contaban con un mayor número de parientes en el hogar y con criados. R. Tovar Pulido (2017c), 209 y $219-221$.

La misma autora analiza la economía y el patrimonio administrado en las jefaturas femeninas extremeñas en R. Tovar Pulido (2020) y (2019). 
desesperación era tal que hasta vendieron en pública almoneda los bienes muebles que les quedaban ${ }^{48}$.

\subsection{Los arrendamientos 0 alquileres}

Las viudas no siempre vendían las propiedades de sus hijos, ya que las rentas derivadas de los alquileres podían sacar de muchos apuros a las familias. En la época moderna, las cartas de arrendamiento eran contratos de arriendo entre dos partes, el arrendador y el arrendatario, por el cual se estipulaba la cesión y disfrute de una propiedad urbana o rústica por un tiempo determinado. El documento recogía la información relativa a las características topográficas del inmueble objeto de arrendamiento, como era la localización, la extensión y/o capacidad. Asimismo, desde el punto de vista contractual, se detallaba el valor de la renta y el modo de pago, junto con la duración del alquiler y para qué sería dedicado (vivienda, explotación agrícola-ganadera... $)^{49}$.

Hemos observado que principalmente se producían arrendamientos de casas, aunque también se hacían de cortijos y de tierras. Un caso ilustrativo es el que nos proporciona una escritura pública de Pozo Alcón, datada el 17 de enero de 1765. Magdalena Pérez, en la carta de arrendamiento, declaraba que tras la muerte de su marido se dejaron unos bienes a sus hijos menores, por lo que había decidido arrendar el cortijo de estos y las tierras, ya que le reportarían 772 reales por la cosecha ${ }^{50}$.

El mantenimiento del hogar les resultaba de gran dificultad cuando su situación económica se veía golpeada por la pobreza. La propiedad de una casa aseguraba tener un lugar donde vivir, mientras que el disfrute de tierras, aunque no fueran muchas, les permitía disponer de rentas con las que sobrevivir. Por el contrario, la ausencia de propiedad alguna desembocaba en la pobreza extrema, sin otra solución que la necesidad de recurrir a la limosna y a la caridad. Asimismo, frente a la mayoría de mujeres más humildes, había un grupo de viudas denominadas de "mediano pasar" o

48. Indica M. García Fernández que, en el interior castellano, las familias desembolsaban en alimento un 5,9\% de los gastos (con oscilaciones entre el 24,2 \% y el 3,7 \% mínimo). El vestido suponía entre un $1 \%$ y el $52 \%$ de los descargos: un reducido 4,9 \% por término medio (oscilaba entre el $49,1 \%$ el más alto y un mínimo del $3 \%$ ). M. García Fernández (2016), 43 y 45.

49. J. L. Pereira Iglesias y M. Rodríguez Cancho (1982), 195.

50. AHPJ, Pozoalcón, años 1764-1768, número 14968, año 1765. Registro de escrituras públicas. Arrendamiento de Magdalena Pérez a otra persona, 17 de enero de 1765, s/f. 
"mediana hacienda", las cuales contaban con un mayor número de propiedades con las que subsistir de forma más desahogada, si bien no de manera tan acomodada como la minoría de mujeres ricas ${ }^{51}$. En cualquier caso, en lo que respecta a Magdalena Pérez, la propiedad de un cortijo y el valor de las rentas anuales que percibiría esta viuda por su arriendo ponen en evidencia que pertenecía a una familia acomodada, de manera que la finalidad del alquiler, lejos de estar relacionado con una situación de penuria económica, era ver incrementado su volumen de ingresos.

\subsection{Los reconocimientos de censos}

Cuando se tenían propiedades hipotecadas era preciso pagar una cantidad anual para saldar las deudas contraídas con la persona o institución que realizó el préstamo, sin el cual no podría haberse adquirido la propiedad. Esta cantidad aparecía recogida a modo de censo. De modo que los reconocimientos de censos regulaban las cantidades que habían de ser pagadas por el disfrute de una propiedad. Así pues, las cartas de imposición de censo reconocían operaciones crediticias que consistían en el préstamo de un capital líquido (denominado principal) por el censualista, el cual lo entregaba al censatario. Este debía amortizarlo y pagar los intereses devengados, así como se fijaban sus bienes como garantía hipotecaria. De acuerdo a la temporalidad, el censo podía ser perpetuo (sin término fijado), redimible (por un número de años estipulado) o al quitar (podía redimirse si se devolvía todo el principal). De manera similar, las cartas de reconocimiento de censo implicaban la aceptación por parte del censatario de la relación contractual establecida y conllevaban la prohibición de enajenar la propiedad por los herederos. También podían ser cartas de censo enfitéutico (por un tiempo determinado), a largo plazo o a perpetuidad, mediante un pago anual de carácter fijo $^{52}$.

Interesante en esta materia porque afecta a una propiedad que se mantiene en la misma familia de hacendados, desde mediados del siglo XVII, y da lugar a un reconocimiento de censo un siglo después es el relativo al menor

51. M. Á. Hernández Bermejo (2019), 12-13 y 16.

La población del siglo XVIII en la España rural estaba condicionada por una desigual distribución de la propiedad, el matrimonio precoz de los hijos y las pautas de residencia neo-local. Todo ello se traducía a nivel demográfico en una baja esperanza de vida y unos elevados niveles de mortalidad. F. García González (2016), 291.

52. J. L. Pereira Iglesias y M. Rodríguez Cancho (1982), 196. 
Cristóbal Gámez. Este se ve implicado en un caso relativo al pago de un censo sobre unos bienes rústicos, pero ante ello responde su representante legal como curadora y tutora, la cual es Isabel de Gámez y Mesía, su tía y familiar consanguíneo en tercer grado, ya que era hermana de su difunto padre. El documento está fechado el 13 de mayo de 1761, en Quesada, y es un reconocimiento de censo de Leonarda de Baena contra Cristóbal de Gámez. Este había heredado de su padre (Juan Gámez Mesía) una finca con un cortijo vinculada a un censo de 200 ducados. El origen del vínculo se remontaba al 19 de febrero del año 1646, cuando su abuelo vinculó dicho censo a diferentes bienes. Este fue reconocido el 29 de marzo de 1736 por su padre y de nuevo el 18 de febrero de 1749. Como consecuencia de los trámites legales que se llevaron a cabo, se fijaron en este documento 850 reales por los devengados de trece años atrás, a favor de Isabel de Gámez y Mesía como curadora y tutora de Cristóbal de Gámez, dueño de las 24 fanegas y el cortijo vinculados ${ }^{53}$.

Se trata de una realidad muy frecuente en los ámbitos rurales, en los que los familiares más cercanos se hacían cargo de defender los intereses patrimoniales de los menores, en los pleitos que tenían su origen en la posesión de la tierra, lo cual era menos habitual en las ciudades ${ }^{54}$.

Esta solidaridad familiar y acogimiento entre tías viudas y sobrinos u otros familiares muchas veces respondía más que a la caridad a una imposición legal, así sucedía al menos con las obligaciones de tutela y de curaduría. Otro ejemplo que también protagoniza una familia acomodada es el referente a Lucena, el 28 de marzo de 1798, cuando se mandó una curaduría a doña Paula María de Angulo y Tamariz, viuda de don Antonio Delgado, la cual era heredera de doña Lucía de Angulo y Tamariz -su hermana-, tutora y curadora de los hijos de esta y, por tanto, sus sobrinos: don Francisco de Asís, doña María del Pilar Delgado y Angulo -menores-, y don Josef Delgado y Angulo -mayor de edad de 25 años-, teniente del regimiento provincial de Córdoba. Todos eran herederos de don Josef Tamariz, por fallecimiento ${ }^{55}$.

53. AHPJ, número 15.108, año 1761. Escribano Juan de Villaseca. Quesada. Reconocimiento de censo de Leonarda de Baena contra don Xristóbal de Gámez, 13 de mayo de 1761, fol. 117

54. M. García Fernández (2016), 52.

55. En 1752 en Lucena aparece una viuda llamada Paula de Angulo, de 40 años y pobre de solemnidad, que mantenía en casa a su madre viuda también. De ser la misma tendría 86 años, de modo que se trataría de un familiar, así como doña Antonia Tamariz de Valderrama, viuda de 39 años en 1752, tenía entonces cinco hijos menores, cuatro de ellos varones, un sirviente y tres sirvientas. 
Observamos en este caso que uno de los tres sobrinos era mayor de edad, por lo que se le impone la curatela, mientras que se reserva la tutela para los dos menores, de cuya alimentación se haría cargo, así como de la administración de sus bienes hasta que alcanzaran su mayoría de edad ${ }^{56}$.

\section{CONCLUSIONES}

En el marco legal castellano del siglo XVIII, las mujeres tenían limitada su capacidad de obrar por la autoridad paterna y marital, de modo que la tutela y la curatela fueron figuras jurídicas que dotaron a las viudas de una interesante autonomía, sobre la administración de los patrimonios heredados por sus hijos o sus sobrinos menores y no emancipados.

Ante la ausencia del pater familias, la práctica legal recurría a la tutela y curatela como sistemas de protección. El tutor era el defensor y guardador del huérfano pupilo menor de 14 años, por lo que se encargaba del cuidado y protección de su persona, junto con la conservación de su patrimonio. Uno de los tipos de tutela más frecuentes era el sistema automático de designación de tutor, donde se incluían la testamentaria y la legítima. En lo que respecta al curador, se ocupaba de los intereses económicos de los menores de entre 14 y 25 años. Para su nombramiento también se seguía el orden de preferencia legítima, testamentaria y dativa. En ambos casos la responsabilidad sobre el menor solía recaer en el cónyuge sobreviviente, la esposa viuda. El discernimiento era el acto jurídico mediante el cual el juez nombraba a la tutora o curadora y la hacía conocedora de sus deberes y obligaciones con respecto a los menores tutelados.

A pesar de que se encargara de administrar los bienes de los menores, la libertad de la mujer se encontraba limitada, en determinadas ocasiones, a la concesión de poderes notariales o cartas de poder. Se trataba de la

AHPC, legajo 3349P, años 1798-1799-1800, fol. 47. Escribano don Antonio Ramírez de Alba. Córdoba, Lucena. Año 1799. Curaduría de Doña Paula María de Angulo y Tamariz, 28 de marzo de 1798. La causa: fallecimiento del padre Josep Tamariz, ella es la tía.

56. Es conveniente tener en cuenta que la tutoría sustituía a la patria potestad ejercida por los progenitores, de manera que para que los jóvenes contrajeran matrimonio requerían de la aprobación o consentimiento de su representante legal, en este caso su tía u otro familiar. Dicho consentimiento es una figura legal de larga tradición en el derecho castellano y, ya desde el siglo XVI, suponía para las familias la cesión de derechos y de la voluntad de los hijos a favor de los padres. Sobre el consentimiento y el matrimonio de los hijos vide J. P. Blanco Carrasco (2016), 110-111. 
cesión de plena potestad para el ejercicio de diversas funciones de naturaleza jurídica o contractual, relativas a la propiedad, como compraventas, arrendamientos y otras cuestiones relativas a la gestión de los bienes.

Una serie de protocolos notariales de poblaciones rurales andaluzas nos han permitido ilustrar la participación de la mujer en dichos documentos públicos en dos vertientes: por un lado, la económica, en la medida en que la gestión de la propiedad nos hace conocedores de los diferentes recursos a los que decidían agarrarse para sobrevivir, ya sea a través de la venta de los bienes, ya sea conservándolos en la familia; si bien aferrándose a la posibilidad de alquilarlos para obtener un dinero que les permitiera seguir adelante, para lo cual recurren a permisos para vender y a cartas de arrendamiento. Del mismo, hemos observado que no se heredaban bienes únicamente, sino que también era preciso hacer frente a la gestión de los préstamos realizados años atrás por otras personas, fuera con censos a favor o en contra, mediante los cuales terceros habían contraído deudas. En este ámbito, observamos cómo las diferencias sociales condicionaron las decisiones que tomaban las viudas sobre la administración de los patrimonios de los menores. Los márgenes de actuación no eran los mismos entre las mujeres acaudaladas y las más humildes, ya que fueron estas últimas las que, en lugar de incrementar los bienes, vieron mermada la herencia de sus hijos debido a situaciones de pobreza que las empujaron a vender lo poco que tenían.

Por otro lado, además de la perspectiva económica, nos resulta de lo más significativa la existencia de testimonios relativos al mundo de los sentimientos de la mujer, en cuanto a sus preocupaciones y temores diarios, fruto de la escasez y de las penurias a las que se vieron abocadas. Relatos como "nos podremos alimentar de las miserias" o "no hallaba asilo ni modo de mantenerme" ilustran muy bien esta cuestión.

\section{BIBLIOGRAFÍA}

Ago, Renata (1996), “Jóvenes nobles en la época del absolutismo: autoritarismo paterno y libertad”, en G. Levi y J. C. Sснмiтt (dirs.), Historia de los jóvenes, vol. I: De la Antigüedad a la Edad Moderna, Taurus, Madrid, pp. 365-413.

Alfaro Pérez, Francisco José (2019), “¿Estrategia familiar o interés individual? Conflictividad paternofilial en la sociedad aragonesa del siglo XVIII", Tiempos Modernos, 9, 38, pp. 310-322.

Arbiol, Antonio (1715), La familia regulada, con doctrina de la Sagrada Escritura, Madrid, por los herederos de Manuel Román, Zaragoza.

ARIĖs, Philippe (1987), El niño y la vida familiar en el Antiguo Régimen, Taurus, Madrid. 1. ${ }^{\mathrm{a}}$ edición: 1960. 
Tutelas y curatelas en la época moderna...

Birriel Salcedo, Margarita María (2019), "Ellas gobiernan la casa: Jefaturas de hogar femeninas en el Valle de Lecrín (s. XVIII)”, Revista del Centro de Estudios Históricos de Granada y su Reino, 31, pp. 57-82.

Blanco Carrasco, José Pablo (2016), "Disensos. Conflictos de la patria potestad en la España rural moderna", Studia Historica. Historia Moderna, 38, 2, pp. 107-135.

Bouneau, Christine et Le Mao, Caroline (dirs.) (2009), Jeunesse(s) et élites. Des rapports paradosaux en Europe de l'Ancien Régime à nos jours, Presses Universitaires, Rennes.

Cava López, María Gema (1999), "Economías infantiles: recursos materiales y gestión del patrimonio de los huérfanos extremeños durante la Edad Moderna", Obradoiro, 8, pp. 65-98.

- (1999-2000), "La tutela de menores en Extremadura durante la Edad Moderna", Revista de Historia Moderna. Anales de la Universidad de Alicante, 18, pp. 265-288.

- (2000), "La protección familiar a la infancia desamparada: huérfanos en Extremadura en tiempos de Felipe II", en E. Martínez Ruiz (dir.), Madrid, Felipe II y las ciudades de la Monarquía, vol. III, Editorial Actas, Madrid, pp. 83-96.

Dubert García, Isidro (1992), Historia de la familia en Galicia durante la época Moderna, 1550-1830, Ediciós do Castro, La Coruña.

Fass, Paula S. (ed.) (2003), The Encyclopedia of the History of Childhood, Gale, New York.

Febrero, José (1828), Febrero Novísimo o librería de jueces, abogados y escribanos, Imprenta de Ildefonso Mompie, Valencia. Edición de don Eugenio de Tapia.

Flandrin, Jean-Louis (1979), Orígenes de la familia moderna, Crítica, Barcelona. Edición original francesa: 1976.

Forns DE Rivera, Cristina (1997), "El ejercicio de la tutela por las mujeres de los ciudadanos de Barcelona (siglos XIII-XIV)", en M. ${ }^{a}$ V. López-Cordón Cortezo y M. Carbonell i Esteller (eds.), Historia de la mujer e historia del matrimonio, Universidad, Murcia, pp. 53-63.

Froide, Amy M. (2005), Never Married. Singlewomen in Early Modern England, University, Oxford.

García Fernández, Máximo (1995), Herencia y patrimonio familiar en la Castilla del Antiguo Régimen (1650-1834): efectos socioeconómicos de la muerte y la partición de bienes, Universidad, Valladolid.

- (2013), "Ya en pleitos desde la más tierna infancia: menores, tutores, litigios", Revista de Demografía Histórica, 31, 2, pp. 87-112.

- (2016), "Tutela y minoría de edad en la Castilla rural: prácticas cotidianas de Antiguo Régimen”, Studia Historica. Historia Moderna, 38, 2, pp. 27-54.

García González, Francisco y Maldonado Cid, Daniel (2019), “Bajo el mismo techo. Los hogares en Andalucía a finales del Antiguo Régimen”, Chronica Nova, 45, pp. 131-163. 
García GonzÁlez, Francisco (2007), "La edad y el curso de la vida: El estudio de las trayectorias vitales y familiares como espejo social del pasado", en F. Chacón Jiménez, J. Hernández Franco y F. García González (eds.), Familia y organización social en Europa y América, siglos $X V$ - $X X$, Universidad, Murcia, pp. 89-108.

— (2016), "Vejez, viudas y soledad rural en la España meridional del siglo XVIII". Studia Histórica: Historia Moderna, 38. pp. 287-324.

Gómez LóPEz, Carlos (2017), “Análisis paleográfico diplomático de las disposiciones testamentarias de Vejer de la Frontera de 1543”, Estudios sobre Patrimonio, Cultura y Ciencias Medievales, 19, 2, pp. 479-536.

Guglielmi, Nilda (1988), "La viuda tutora (Italia del centro y del norte. Siglos XIII-XV)", Anuario de Estudios Medievales, 18, pp. 157-171.

Hernández Bermejo, María Ángeles (2019), "Las mujeres al frente del hogar: viudas, solteras y casadas con marido ausente en Extremadura en la segunda mitad del siglo XVI", Revista del Centro de Estudios Históricos de Granada y su Reino, 31, pp. 7-19.

Lasarte Álvarez, Carlos (2019), Principios de Derecho Civil, tomo VI: Derecho de Familia, Marcial Pons, Madrid. 18. ${ }^{\mathrm{a}}$ ed.

Levi, Giovanni y Schmitt, Jean Claude (dirs.) (1996), Historia de los jóvenes, vol. I: De la Antigüedad a la Edad Moderna, Taurus, Madrid.

Marchant RiverA, Alicia (2009), "El prohijamiento, la tutela y la carta de aprendiz: instrumentos para una historia de la situación del menor en Málaga durante la primera mitad del siglo XVI", en J. J. Bravo Caro y J. SAnZ Sampelayo, (coords.), Población y grupos sociales en el Antiguo Régimen, vol. II, Universidad, Málaga, pp. 943-956.

Martín JimÉnez de MuÑAnA, Miguel (1993), "Estructura de las escrituras notariales de poder en Extremadura en el siglo XVI: estudio de un caso singular", Anuario de la Facultad de Derecho. Universidad de Extremadura, 11, pp. 373-380.

Melgarejo, Pedro (1704), Compendio de Contratos Públicos, autos de particiones. Madrid. Primera ed.: 1674.

Merchán Álvarez, Antonio (1976), La tutela de los menores en Castilla hasta fines del siglo XV, Universidad, Sevilla.

Monterroso y Alvarado, Gabriel de (1571), Práctica civil y criminal e instrucción de escribanos, en casa de Andrés de Angulo, Alcalá de Henares.

NúÑEZ RoldÁn, Francisco (2011), "Fuentes y metodología para el estudio de la infancia rural: las tutelas y las cuentas de menores en los siglos XVI y XVII", en F. NúÑez RoldÁn (ed.), La infancia en España y Portugal. Siglos XVI-XIX, Sílex, Madrid, pp. 133-148.

Pereira Iglesias, José Luis y Rodríguez Cancho, Miguel (1982), “Estructura y tipología de las fuentes notariales en Cáceres y su Tierra durante los tiempos modernos", Norba. Revista de Arte, Geografia e Historia, 3, pp. 191-204. 
Pierrer, Sylvie (1995), “Roles des réseaux de parenté dans l'education des mineurs orphelins selon les comptes de tutelle parisiens (XVIIe-XVIIIe siécles)", Annales de Démographie Historique, pp. 125-135.

Redondo, Agustin (ed.), (1996), La formation de l'enfant en Espagne aux XVIe et XVIIe siècles, Publications de la Sorbonne, Paris.

Roberts, Benjamin B. y Groenendis, Leendert (2005), "Moral Panic and Holland's Libertine Youth of the 1650s and 1660s", Journal of Family History, 30, pp. 327-346.

Roberts, Benjamin. B. (2004), “Wearing Out a Pair of Fool's Shoes'. Sexual Advice for Youth in Holland's Golden Age", Journal of the History of Sexuality, 13, pp. 139-156.

- (2006), “The 'Marlboro Men’ of the Early Seventeenth-Century. Masculine Role Models for Dutch Youths in the Golden Age?", Men and Masculinities, 9, pp. 76-94.

Rodríguez SÁnchez, Ángel (1990), “El poder familiar: la patria potestad en el Antiguo Régimen”, Chronica Nova, 18, pp. 365-380.

Salas Auséns, José Antonio (2014), "La cenicienta no era un cuento", en F. J. Alfaro Pérez (coord.), Familias rotas: conflictos familiares en la España de fines del Antiguo Régimen, Universidad, Zaragoza, pp. 169-208.

Tovar Pulido, Raquel (2014-2015), "Entre la marginalidad y la soledad: las viudas de Vilches (Jaén) a mediados del siglo XVIII", Norba. Revista de Historia, 27-28, pp. 405-420.

- (2017a), "La riqueza patrimonial de las familias de las viudas jiennenses en el siglo XVIII", Cuadernos de Historia Moderna, 42, 1, pp. 195-220.

- (2017b), "Pobres, hacendadas, comerciantes y otros oficios: economías femeninas y estructura de la familia entre las viudas de finales del Antiguo Régimen (Trujillo)", Studia Historica. Historia Moderna, 39, 2, pp. 397-432.

- $(2017 \mathrm{c})$, “Organización doméstica y procesos de reproducción social en una ciudad de la Alta Extremadura en el final de los tiempos modernos: Trujillo", Estudios de Historia de España, 19, pp. 199-224.

- (2018a), "Viudas hacendadas y labradoras: la propiedad femenina en el noreste andaluz a mediados del siglo XVIII (el Reino de Jaén)", en M. Á. Pérez Samper y J. L. Beltrán Moya, (coords.), Nuevas perspectivas de investigación en Historia Moderna: economía, sociedad, política y cultura en el mundo hispánico, Universidad de Barcelona, Universidad Autónoma de Barcelona y Fundación Española de Historia Moderna, Barcelona, pp. 317-331.

- (2018b), "Familia y jefatura del hogar a finales del reinado de Fernando VII: la ciudad de Trujillo", Relaciones. Estudios de Historia y Sociedad, 39, 154, pp. 137-172.

- (2019), “Individuos y espacios domésticos: estrategias de transmisión patrimonial de las mujeres viudas en la España rural (Extremadura, siglo XVIII)", Studia Europaea Gnesnensia, 19, pp. 271-287. 
— (2020), "Mujeres en la jefatura del hogar, trabajo y riqueza patrimonial en Trujillo durante la segunda mitad del siglo XVIII", en R. Tovar Pulido (coord.), De humilde e ilustre cuna: retratos familiares de la España Moderna (siglos $X V$-XIX). Coleção Biblioteca-Estudos \& Colóquios. CIDEHUS-Universidad, Évora, pp. 153-178.

VigIL, Marilo (1986), La vida de las mujeres en los siglos XVI y XVII, Siglo XXI de España, Madrid.

ZÚÑIGA, Ángeles (2013), “QQué es y para qué se utiliza un poder notarial?”, Escritura Pública, 80, pp. 64-67. 